\title{
Total synthesis of selected natural products
}

\author{
K. C. Nicolaou*, E. W. Yue
}

Department of Chemistry, The Scripps Research Institute, 10666 North Torrey Pines Road, La Jolla, California 92037 and Department of Chemistry and Biochemistry, University of California, San Diego, 9500 Gilman Drive, La Jolla, California 92093

Abstract: Natural products continue to provide ever-increasing challenges to synthetic chemists with their complex and sensitive structures. With proper selection, these challenges can be turned into wonderful opportunities to invent and discover new synthetic reactions, to design new strategies and to fashion novel molecular architectures. Developments in these areas often profoundly influence and shape the science of chemical synthesis, biology and medicine. In this article, a number of recent total syntheses of challenging natural substances from the authors's laboratories are highlighted.

\section{Introduction}

The art of constructing the molecules of nature continues to attract and fascinate synthetic organic chemists, for it provides an arena where creativity and imagination, stamina and character
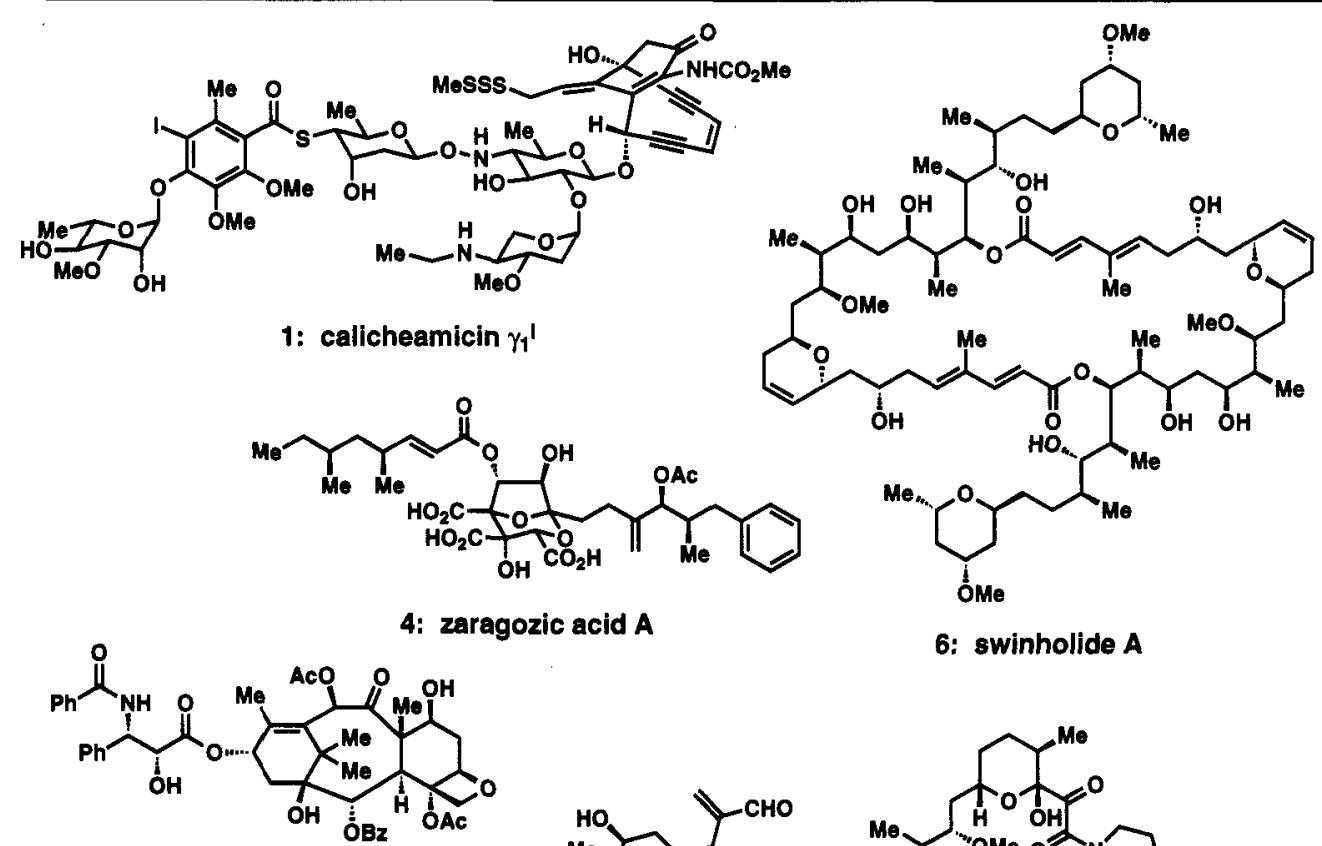

3: TaxolTM

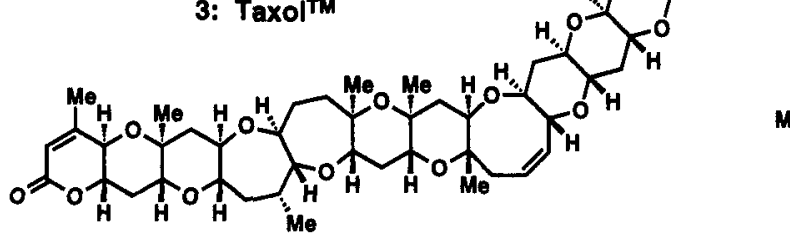

5: brevetoxin B

6: swinholide A

Figure 1. Structures of selected natural products synthesized in the Nicolaou laboratories (1992-96). 
can make a difference and amply shine. Coupled with the intellectual challenge are often the opportunities to discover and invent new reactions and strategies, to probe biological questions and to make contributions to medicine. ${ }^{1}$ It is these characteristics that make the field of total synthesis as exciting and vigorous as it is today and as it will continue to be for some time to come.

Since the landmark syntheses of urea and acetic acid in 1828 and 1845 respectively, synthetic chemists have come a long way in terms of complexity of the targets they can consider, and efficiency by which these targets can be reached.

In our laboratories the challenges posed by natural products are carefully selected and the art is practiced first and foremost for its own sake, but also for the opportunities it presents in discovering and testing new reactions and in molecular design for the purposes of chemical synthesis, biology and medicine. In this article we focus on the total synthesis aspects of some of our recent programs in natural products and outline briefly the evolution of the strategies involved. We shall discuss the total synthesis of calicheamicin $\gamma_{1}^{\prime}(1)$, rapamycin (2), TaxolTM (3), zaragozic acid $A(4)$, brevetoxin $B(5)$, and swinholide A (6) (see Fig. 1).

\section{Calicheamicin $\gamma_{1}^{\prime}$}

The fascination with calicheamicin $\gamma_{1}^{\prime}(1)^{2}$ derives from its novel molecular architecture, its phenomenal cytotoxic activity against tumor cells, and its mechanism of action and these aspects have been amply discussed previously. ${ }^{3}$ Figure 2 depicts the strategic bond disconnections that led to the final strategy for the total synthesis of calicheamicin $\gamma_{1}^{1 ., 5}$ This convergent strategy

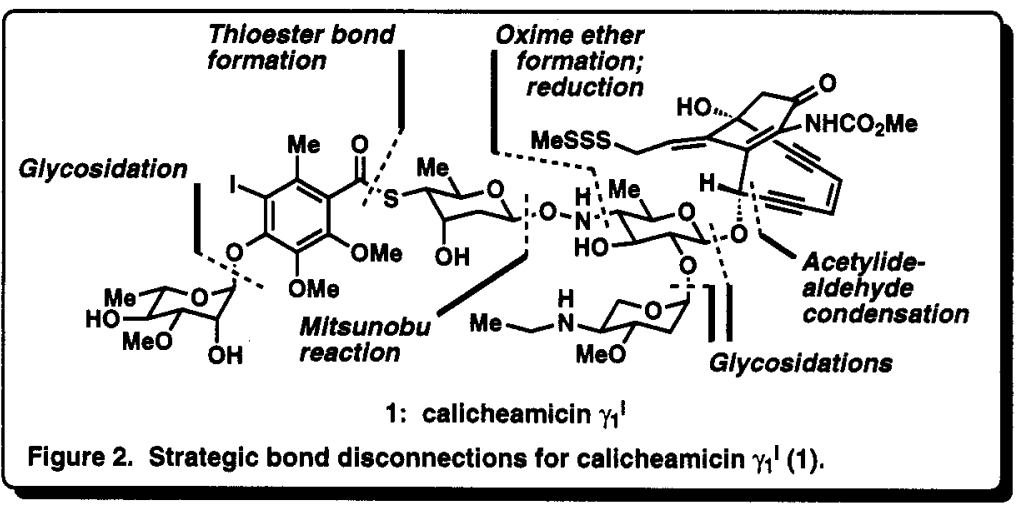
involved: (a) coupling of the oligosaccharide domain with the enediyne fragment via glycosidation with the trichloroacetimidate method; (b) an intramolecular acetylidealdehyde condensation to construct the 10 membered ring enediyne core; (c) a Mitsunobu-type glycosidation to install the $\mathrm{O}-\mathrm{NH}$ bond; (d) an oxime ether formation followed by reduction to form the $\mathrm{C}-\mathrm{NH}$ bond; and (e) a thioester bond formation to join the $A B$ and CDE ring systems and glycosidation reactions for the attachments of rings $A$ and $E$. The precise order of these couplings and the intricate details of the story have been extensively reviewed. ${ }^{6-8}$

\section{Rapamycin}

The appeal of rapamycin $(2)^{9}$ as a synthetic target emanates from its novel molecular structure, its immunosuppressive properties and its intriguing mode of action. These issues and the details of its total synthesis in our laboratories have been extensively discussed in the literature..$^{10 \cdot 13}$ Herein, we outline retrosynthetically (Fig. 3) the main coupling reactions used in the construction. The ester and amide bonds were utilized as convenient linkages to assemble a large part of

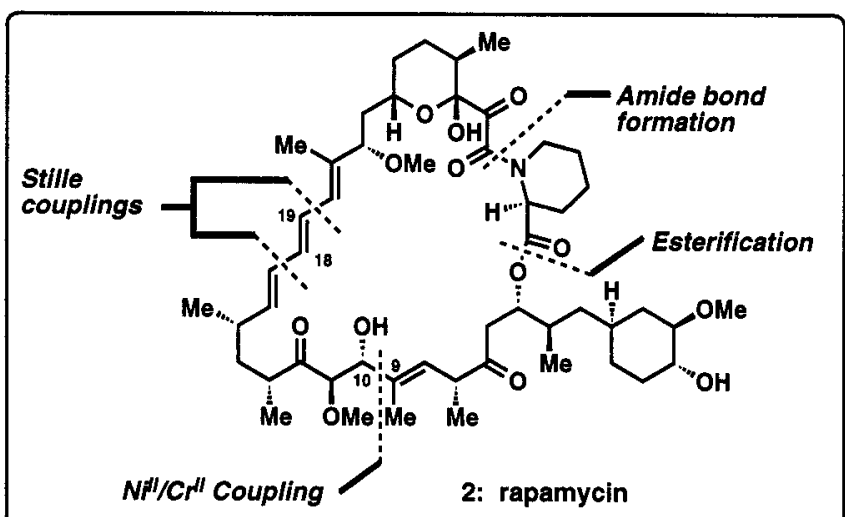

Figure 3. Strategic bond disconnections for rapamycin (2). 
the molecule. The $\mathrm{C} 9-\mathrm{C} 10$ carbon-carbon bond was formed by a $\mathrm{Ni} / \mathrm{Cr} \mathrm{r}^{\prime \prime}$ coupling reaction. The most impressive reaction, however, in this total synthesis was the double Stille reaction of vinyldistannane with the corresponding bis(vinyl iodide) which resulted in the simultaneous construction of the sensitive conjugated triene system and the macrocyclic skeleton. This new strategy for the construction of macrocycles pointed the way for several new applications in total synthesis proving itself as a highly valuable method.

\section{TaxolTM}

The molecule of $\operatorname{Taxol}^{\mathrm{TM}}(3)^{14}$ needs very little, if any, introduction to the audience of synthetic chemists. Its structure, mechanism of action and clinical use in cancer therapy have fascinated scientists and benefited patients around the world for some time..$^{15}$ Finally, Taxol ${ }^{T M}$ yieided to total synthesis in $1994 .{ }^{16,17}$ Figure 4 depicts, in retrosynthetic terms, the key disconnections that led to the evolution of our successful strategy towards this important molecule. Thus, Diels-

Alder reactions led to rapid

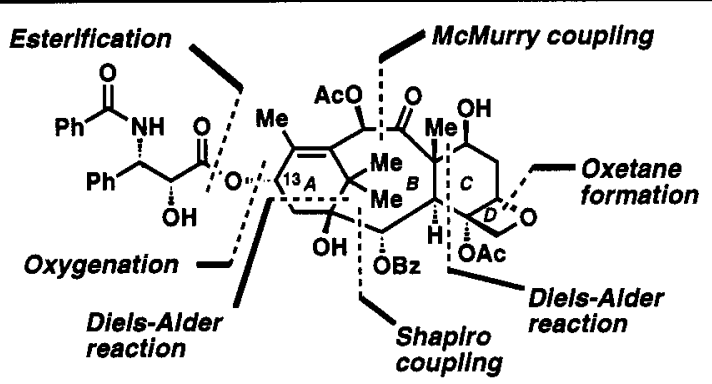

3: Taxol $^{\mathrm{TM}}$ constructions of rings $A$ and $C$ while Shapiro and McMurry couplings allowed the construction of the 8-membered ring system (ring B). An SN2 type displacement was utilized for the installment of the oxetane ring system, whereas an allylic oxygenation implanted the desired oxygen at $\mathrm{C}-13$ where the side chain was attached via esterification. The convergency of the sequence and its flexibility for analog construction are noteworthy features. ${ }^{18-}$

Figure 4. Strategic bond disconnections for $\operatorname{Taxol}^{\mathrm{TM}}(3)$. 21

\section{Zaragozic Acid A}

The zaragozic acids (squalestatins) are a new and fascinating class of natural products with marked cholesterol lowering properties. Their chemistry and biology has recently been reviewed. ${ }^{22,23}$ Due to its unique structure and important biological actions, zaragozic acid $A(4)^{24,25}$ became, soon after its structural elucidation, an attractive synthetic target. Our total synthesis made use of the strategic bond disconnections shown in Fig. 5.2629 An intriguing acid-induced rearrangement led to the highly oxygenated core of the structure, whereas a dithiane anion-aldehyde condensation and an esterification completed the skeleton of zaragozic acid $A$.

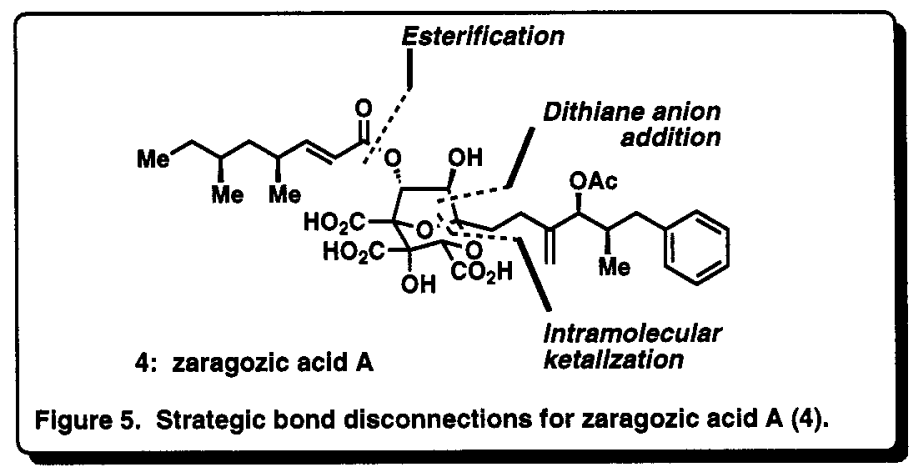

\section{Brevetoxin B}

Brevetoxin B (5), one of the most prominent neurotoxins of the notorious "red tides" has provided much challenge, stimulus and excitement ever since its initial discovery. ${ }^{30}$ It finally succumbed to total synthesis on October $20,1995 . .^{31,32}$ The 12-year "odyssey" leading up to this synthesis has recently been published $\mathrm{d}^{33}$ and we will only touch upon the highlights here. ${ }^{34}$ Figure 6 illustrates the main strategic bond disconnections that point the way to the final strategy for this construction. Thus, a Wittig reaction and a hydroxy dithioketal cyclization were used to couple the $A B C D E F G$ and IJK ring systems and construct the basic brevetoxin skeleton by forming the oxocene ring $(\mathrm{H})$. A newly developed $\mathrm{Ni}^{\prime \prime} / \mathrm{Cr}^{\prime \prime}$ coupling method for joining vinyl triflates derived from lactones 


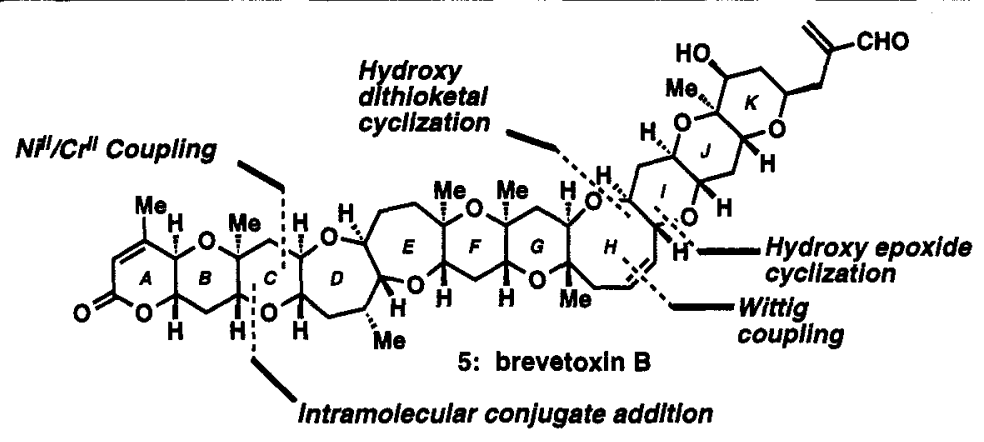

Figure 6. Strategic bond disconnections for brevetoxin B (5).

and aldehydes was applied to construct the indicated carbon-carbon bond of ring $\mathrm{C}$, whereas a conjugate addition of a hydroxy group to an $\alpha, \beta-$ unsaturated ester led to the closure of this ring (C) ${ }^{35-37}$

The oxepane rings were sequentially formed as lactones and subsequently converted to the desired ether functionalities, whereas ring A was installed via an intramolecular Horner-Wadsworth-Emmons reaction. The 6-membered ring systems were constructed starting with carbohydrates and using regioselective and stereospecific hydroxyepoxide openings. The final target was reached from 2deoxy-D-ribose in 83 steps (longest linear sequence with an average yield of $91 \%$ per step).

\section{Swinholide A}

Our total synthesis of swinholide A (6), a novel and highly potent cytotoxic agent isolated from marine sources, ${ }^{38}$ featured a number of new reactions and strategies..$^{39,40}$ The main strategic bond disconnections are indicated in Fig. 7 and they include: two esterification reactions, two Horner-WadsworthEmmons reactions, two dithiane-cyclic sulfate couplings and two Ghosez cyclizations. The utilization of the sulfate opening and of the Ghosez cyclization to construct the dihydropyran systems demonstrated the power of these reactions in the total synthesis of complex molecules and allowed complete stereocontrol at the

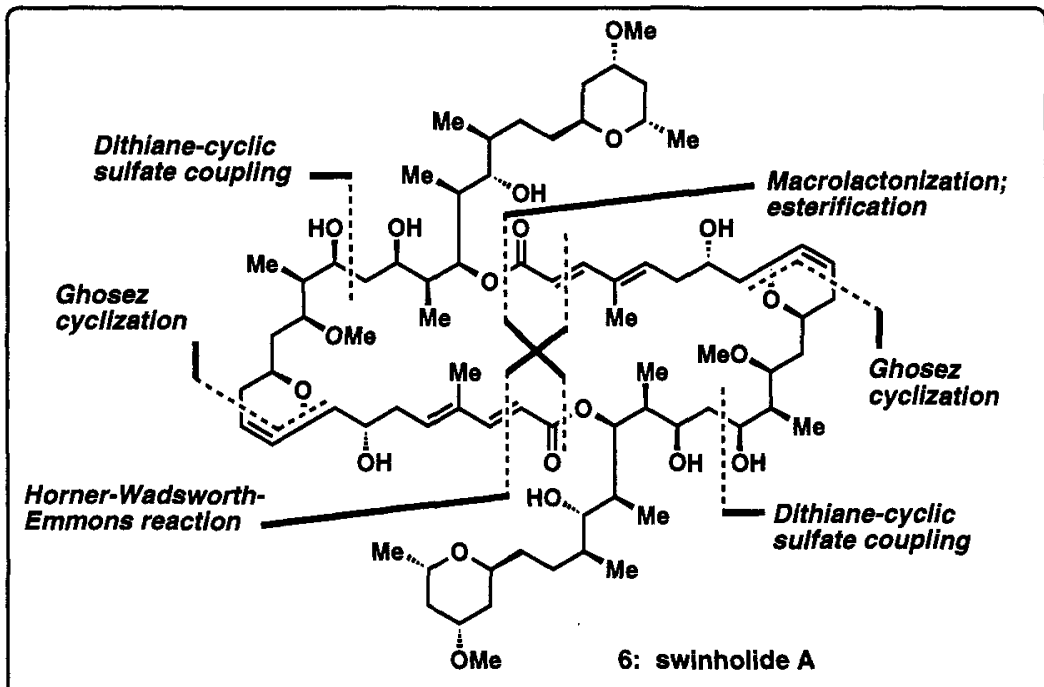

Figure 7. Strategic bond disconnections for swinholide A (6). involved sites.

\section{Conclusion}

In this article a brief synopsis of several projects in the author's laboratories involving total synthesis has been given. Whereas further details can be found in the literature cited, these highlights may well serve to underscore challenges involved in total synthesis and to point out the various ways that such challenges are currently faced by contemporary synthetic technology. Left out from this article are the equally important methodological advancements and inventions encountered during these synthetic "odysseys" and the biological studies that accompanied them. For those aspects, the reader is referred to the cited literature. For an attractive account of some of these and other total syntheses, the reader is referred to "Classics in Total Synthesis". ${ }^{41}$ 
Acknowledgments. We would like to express our gratitude and appreciation to all our co-workers, whose names appear in the references, for their contributions to the research described in this article. Our programs have been financially supported by the National Institutes of Health, Merck, Sharp and Dohme, Glaxo, Schering Plough, Pfizer, Hoffmann La Roche, and the ALSAM Foundation.

\section{References}

1. K. C. Nicolaou, E. A. Theodorakis and C. F. Claiborne, Pure Appl. Chem., in press.

2. (a) M. D. Lee, T. S. Dunne, M. M. Siegel, C. C. Chang, G. O. Morton and D. B. Borders, J. Am. Chem. Soc. 109, 3464 (1987); (b) M. D. Lee, T. S. Dunne, C. C. Chang, G. A. Ellestad, M. M. Siegel, G. O. Morton, W. J. McGahren and D. B. Borders, J. Am. Chem. Soc. 109, 3466 (1987); (c) M. D. Lee, T. S. Dunne, C. C. Chang, M. M. Siegel, G. O. Morton, G. A. Ellestad, W. J. McGahren and D. B. Borders, J. Am. Chem. Soc. 114, 985 (1992).

3. K. C. Nicolaou and W.-M. Dai, Angew. Chem. Int. Ed. Engl. 30, 1387 (1991).

4. K. C. Nicolaou, C. W. Hummel, E. N. Pitsinos, M. Nakada, A. L. Smith, K. Shibayama and H. Saimoto, J. Am. Chem. Soc. 114, 10082 (1992).

5. K. C. Nicolaou, Angew. Chem. Int. Ed. Engl. 32, 1377 (1993).

6. R. D. Groneberg, T. Miyazaki, N. A. Stylianides, T. J. Schulze, W. Stahl, E. P. Schreiner, T. Suzuki, Y. Iwabuchi, A. L. Smith and K. C. Nicolaou, J. Am. Chem. Soc. 115, 7593 (1993).

7. A. L. Smith, E. Pitsinos, C.-K. Hwang, Y. Mizuno, H. Saimoto, G. R. Scarlato, T. Suzuki and K. C. Nicolaou, J. Am. Chem. Soc. 115, 7612 (1993).

8. K. C. Nicolaou, C. W. Hummel, M. Nakada, K. Shibayama, E. N. Pitsinos, H. Saimoto, Y. Mizuno, K.-U. Baldenius and A. L. Smith, J. Am. Chem. Soc. 115, 7625 (1993).

9. (a) C. Vezina, A. Kudelski and S. N. Sehgal, J. Antibiot. 28, 721 (1975); (b) S. N. Sehgal, H. Baker and C. Vezina, J. Antibiot. 28, 727 (1975); (c) D. C. N. Swindells, P. S. White and J. A. Findlay, Can. J. Chem. 56, 2491 (1978); (d) J. A. Findlay and L. Radics, Can. J. Chem. 58, 579 (1980).

10. A. D. Piscopio, N. Minowa, T. K. Chakraborty, K. Koide, P. Bertinato and K. C. Nicolaou, J. Chem. Soc., Chem. Commun. 617 (1993).

11. K. C. Nicolaou, P. Bertinato, A. D. Piscopio, T. K. Chakraborty and N. Minowa, J. Chem. Soc., Chem. Commun. 619 (1993).

12. K. C. Nicolaou, T. K. Chakraborty, A. D. Piscopio, N. Minowa and P. Bertinato, J. Am. Chem. Soc. 115, 4419 (1993).

13. K. C. Nicolaou, A. D. Piscopio, P. Bertinato, T. K. Chakraborty, N. Minowa and K. Koide, Chem. Eur. J. 1, 318 (1995).

14. M. C. Wani, H. L. Taylor, M. E. Wall, P. Coggen and A. McPhail, J. Am. Chem. Soc. 93, 2325 (1971)

15. K. C. Nicolaou, W.-M. Dai and R. K. Guy, Angew. Chem. Int. Ed. Engl. 33, 15 (1994).

16. Z. Yang, J.-J. Liu, H. Ueno, P. G. Nantermet, R. K. Guy, C. F. Claiborne, J. B. Renaud, E. A. Couladouros, K. Paulvannan and E. J. Sorensen, Nature 367, 630 (1994).

17. K. C. Nicolaou and R. K. Guy, Angew. Chem. Int. Ed. Engl. 34, 2079 (1995).

18. K. C. Nicolaou, P. G. Nantermet, H. Ueno, R. K. Guy, E. A. Couladouros and E. J. Sorensen, J. Am. Chem. Soc. 117, 624 (1995).

19. K. C. Nicolaou, J.-J. Liu, Z. Yang, H. Ueno, E. J. Sorensen, C. F. Claiborne, R. K. Guy, C.-K. Hwang, M. Nakada and P. G. Nantermet, J. Am. Chem. Soc. 117, 634 (1995).

20. K. C. Nicolaou, Z. Yang, J.-J. Liu, P. G. Nantermet, C. F. Claiborne, J. Renaud, R. K. Guy and K. Shibayama, J. Am. Chem. Soc. 117, 645 (1995).

21. K. C. Nicolaou, H. Ueno, J.-J. Liu, P. G. Nantermet, Z. Yang, J. Renaud, K. Paulvannan and R. Chadha, J. Am. Chem. Soc. 117, 653 (1995).

22. A. Nadin and K. C. Nicolaou, Angew. Chem. Int. Ed. Engl., in press.

23. N. S. Watson and P. A. Procopiou, In Progress in Medicinal Chemistry (G. P. Ellis and D. K. Luscombe, Eds.), Vol. 33, Ch. 7. Elsevier, Amsterdam (1996). 
24. J. D. Bergstrom, M. M. Kurtz, D. J. Rew, A. M. Amend, J. D. Karkas, R. G. Bostedor, V. S. Bansal, C. Dufresne, F. L. VanMiddlesworth, O. D. Hensens, J. M. Liesch, D. L. Zink, K. E. Wilson, J. Onishi, J. A. Milligan, G. Bills, L. Kaplan, M. Nallin Omstead, R. G. Jenkins, L. Huang, M. S. Meinz, L. Quinn, R. W. Burg, Y. L. Kong, S. Mochales, M. Mojena, I. Martin, F. Pelaez, M. T. Diez and A. W. Alberts, Proc. Natl. Acad. Sci. USA 90, 80 (1993).

25. (a) M. J. Dawson, J. E. Farthing, P. S. Marshall, R. F. Middleton, M. J. O'Neill, A. Shuttleworth, C. Stylli, R. M. Tait, P. M. Taylor, H. G. Wildman, A. D. Buss, D. Langley and M. V. Hayes, J. Antibiot. 45, 639 (1992); (b) P. J. Sidebottom, R. M. Highcock, S. J. Lane, P. A. Procopiou and N. S. Watson, J. Antibiot. 45, 648 (1992).

26. K. C. Nicolaou, A. Nadin, J. E. Leresche, S. La Greca, T. Tsuri, E. W. Yue and Z. Yang, Angew. Chem. Int. Ed. Engl. 33, 2184 (1994).

27. K. C. Nicolaou, E. W. Yue, Y. Naniwa, F. De Riccardis, A. Nadin, J. E. Leresche, S. La Greca and Z. Yang, Angew. Chem. Int. Ed. Engl. 33, 2187 (1994).

28. K. C. Nicolaou, A. Nadin, J. E. Leresche, E. W. Yue and S. La Greca, Angew. Chem. Int. Ed. Engl. 33, 2190 (1994).

29. K. C. Nicolaou, E. W. Yue, S. La Greca, A. Nadin, Z. Yang, J. E. Leresche, T. Tsuri, Y. Naniwa and F. De Riccardis, Chem. Eur. J. 1, 467 (1995).

30. (a) Y.-Y. Lin, M. Risk, S. M. Ray, D. Van Engen, J. Clardy, J. Golik, J. C. James and K. Nakanishi, J. Am. Chem. Soc. 103, 6773 (1981); (b) M. S. Lee, D. J. Repeta, K. Nakanishi and M. G. Zagorski, J. Am. Chem. Soc. 108, 7855 (1986).

31. K. C. Nicolaou, E. Theodorakis, F. P. J. T. Rutjes, J. Tiebes, M. Sato, E. Untersteller and X.-Y. Xiao, J. Am. Chem. Soc. 117, 117.1 (1995).

32. K. C. Nicolaou, F. P. J. T. Rutjes, E. Theodorakis, J. Tiebes, M. Sato and E. Untersteller, J. Am. Chem. Soc. 117, 1173 (1995).

33. K. C. Nicolaou, Angew. Chem. Int. Ed. Engl. 35, 588 (1996).

34. K. C. Nicolaou and E. A. Theodorakis, Pure Appl. Chem., in press.

35. K. C. Nicolaou, C.-K. Hwang, M. E. Duggan, D. A. Nugiel, Y. Abe, K. Bal Reddy, S. A. DeFrees, D. R. Reddy, R. A. Awartani, F. P. J. T. Rutjes and E. A. Theodorakis, J. Am. Chem. Soc. 117, 10227 (1995).

36. K. C. Nicolaou, E. A. Theodorakis, F. P. J. T. Rutjes, M. Sato, J. Tiebes, X.-Y. Xiao, C.K. Hwang, M. E. Duggan, Z. Yang, E. A. Couladouros, F. Sato, J. Shin, H.-M. He and T. Bleckman, J. Am. Chem. Soc. 117, 10239 (1995).

37. K. C. Nicolaou, F. P. J. T. Rutjes, E. A. Theodorakis, J. Tiebes, M. Sato and E. Untersteller, J. Am. Chem. Soc. 117, 10252 (1995).

38. (a) S. Carmely and Y. Kashman, Tetrahedron Lett. 26, 511 (1985); (b) M. Kobayashi, J. Tanaka, T. Katori, M. Matsura and I. Kitagawa, Tetrahedron Lett. 30, 2963 (1989);

(c) M. Doi, T. Ishida, M. Kobayashi and I. Kitagawa, J. Org. Chem. 56, 3629 (1991);

(d) I. Kitagawa, M. Kobayashi, T. Katori and M. Yamashita, J. Am. Chem. Soc. 112, 3710 (1990); (e) M. Kobayashi, J. Tanaka, T. Katori, M. Yamashita, M. Matsura and I. Kitagawa, Chem. Pharm. Bull. 38, 2409 (1990); (f) M. Kobayashi, J. Tanaka, T. Katori and I. Kitagawa, Chem. Pharm. Bull. 38, 2960 (1990).

39. K. C. Nicolaou, K. Ajito, A. P. Patron, H. Khatuya, P. K. Richter and P. Bertinato, J. Am. Chem. Soc. 118, 3059 (1996).

40. K. C. Nicolaou, A. P. Patron, K. Ajito, P. K. Richter, H. Khatuya, P. Bertinato, R. A. Miller and M. J. Tomaszewski, Chem. Eur. J., in press.

41. K. C. Nicolaou and E. J. Sorensen, Classics in Total Synthesis, VCH, Weinheim (1996). 